\title{
Freak waves of different types in the coastal zone of the Baltic Sea
}

\author{
I. Didenkulova ${ }^{1,2}$ and C. Anderson ${ }^{3}$ \\ ${ }^{1}$ Laboratory of Wave Engineering, Institute of Cybernetics, Tallinn, Estonia \\ ${ }^{2}$ Department of Nonlinear Geophysical Processes, Institute of Applied Physics, Nizhny Novgorod, Russia \\ ${ }^{3}$ Department of Probability and Statistics, University of Sheffield, Sheffield, UK
}

Received: 9 June 2010 - Revised: 5 August 2010 - Accepted: 11 August 2010 - Published: 30 September 2010

\begin{abstract}
We present a statistical analysis of freak waves ${ }^{1}$ measured during the $203 \mathrm{~h}$ of observation on sea surface elevation at a location in the coastal zone of the Baltic Sea (2.7 $\mathrm{m}$ depth) during June-July 2008. The dataset contains 97 freak waves occurring in both calm and stormy weather conditions. All of the freak waves are solitary waves, $63 \%$ of them having positive shape, $17.5 \%$ negative shape and $19.5 \%$ sign-variable shape. It is suggested that the freak waves can be divided into two groups. Those of the first group, which includes $92 \%$ of the freak waves, have an amplification factor (ratio of freak wave height to significant wave height) which does not vary from significant wave height and has values largely within the range of 2.0 to 2.4; while for the second group, which contain the most extreme freak waves, amplification factors depend strongly on significant wave height and can reach 3.1. Analysis based on the Generalised Pareto distribution is used to describe the waves of the first group and lends weight to the identification of the two groups. It is suggested that the probable mechanism of the generation of freak waves in the second group is dispersive focussing. The time-frequency spectra of the freak waves are studied and dispersive tracks, which can be interpreted as dispersive focussing, are demonstrated.
\end{abstract}

\section{Introduction}

There has been much recent interest in the problem of freak (rogue) wave occurrence. It has been realised that in many situations, extreme single waves can cause significant damage to marine structures and even lead to failure, and a num-

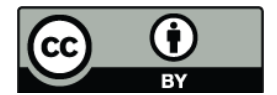

Correspondence to: I. Didenkulova (ira@cs.ioc.ee)

${ }^{1}$ taken to be waves whose height is 2 or more times greater than the significant wave height ber of ship accidents have been caused by freak waves (Toffoli et al., 2005; Didenkulova et al., 2006). As a result, much attention has been paid to freak wave occurrence in the deep part of the ocean with regards to ship accidents and damage to ocean platforms. The North and Norwegian Sea, from which many accidents have been reported, has become a focus of intense study of freak waves (Magnusson et al., 1999; Bitner-Gregersen and Magnusson, 2004; Guedes Soares et al., 2004; Stansell, 2004; Walker et al., 2004; Petrova et al., 2006; Krogstad et al., 2008; Olagnon, 2008), but extreme wave data have also been analysed for the Mediterranean (Prevosto et al., 2000), Japan Sea (Mori and Yasuda, 2002), Gulf of Mexico (Al-Humoud et al., 2002) and Kuwaiti territorial waters (Neelamani et al., 2007). Different theoretical models of freak wave generation have been developed (Olagnon and Athanassoulis, 2001; MaxWave, 2003; Kharif and Pelinovsky, 2003; Kharif et al., 2009).

Freak wave events are also observed near shore, where they can lead to damage to coastal structures and loss of life. For example, Chien et al. (2002), report on 140 freak wave events in the coastal zone of Taiwan for the past 50 years (1949-1999) and Didenkulova et al. (2006), report on coastal freak wave events seen by casual eyewitnesses in 2005. The increased incidence of such accidents suggests more widespread coastal freak wave occurrence than has hitherto been recognized. Usually freak events onshore result in sudden short-term flooding of the coast, or a strong impact upon steep banks or coastal structures. Some descriptions of such events are given in Dean and Dalrymple (2002) and Kharif et al. (2009). General properties of wind-wave background in shallow water are studied, for example, in Glukovskij (1966), Bitner (1980), Massel (1989, 1996), and Young and Babanin (2009).

The properties of coastal freak waves and the mechanisms of their formation differ from those developed for deep waters, and need to be studied. This paper presents an analysis of data on freak waves occurring in the coastal zone of the

Published by Copernicus Publications on behalf of the European Geosciences Union. 


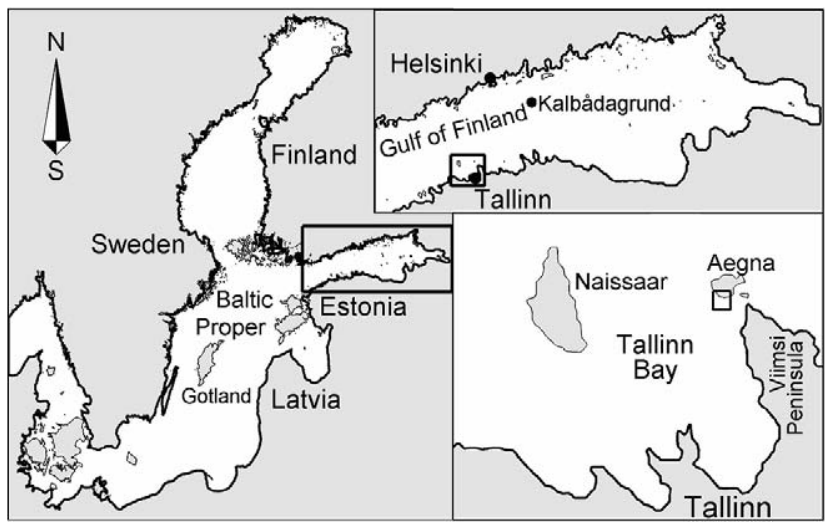

Fig. 1. The Baltic Sea, Tallinn Bay, the study site on the SW coast of Aegna (right lower panel).

Baltic Sea. The characteristic features of the Baltic Sea and the observation site are described in Sect. 2, together with details of the experiment and measurement methods. The general properties of the observed freak waves (wave heights, wave asymmetry and wave shapes) are described in Sect. 3. In Sect. 4, two putative groups of freak waves are identified in terms of the amplification factors and their variations with significant wave height. The first group, Group I (amplification factors vary over a limited range (from 2.0 to 2.4 ) and do not depend on significant wave height), the largest of the two, containing $92 \%$ of the freak waves observed, is discussed in Sect. 5. The second group, Group II, contains more extreme waves with amplification factors reaching as high as 3.1 in the dataset, and showing strong dependence on significant wave height. This group is studied in Sect. 6. It is suggested that the probable mechanism of the generation of waves in this group is dispersive focussing. The paper concludes with a summary of findings in Sect. 7.

\section{Study site and wave measurements}

Tallinn Bay is a semi-enclosed body of water, approximately $10 \times 20 \mathrm{~km}$ in size, with the City of Tallinn located at its southern end. The bay belongs to a family of semi-sheltered bays that penetrate deep into the southern coast of the Gulf of Finland (Fig. 1), an elongated sub-basin of the Baltic Sea. The overall hydrodynamic activity is fairly limited in this almost-tideless area. There are, however, extensive water level variations driven primarily by weather systems, with a maximum recorded range of $2.42 \mathrm{~m}$. As very high (more than $1 \mathrm{~m}$ a.m.s.l.) water level events are rare, the wind-wave impact is concentrated into a relatively narrow range in the coastal zone.

The complex shape of the Baltic Sea, combined with the anisotropy of predominant winds, results in a particular local wave climate in Tallinn Bay. Most storms blow from the SW but occasionally very strong NNW storms occur. Long and high waves created in the Baltic Proper during SW storms usually do not enter the Gulf of Finland owing to geometrical blocking (Caliskan and Valle-Levinson, 2008). Bottom refraction at the mouth of the Gulf of Finland may cause waves to enter the gulf under certain circumstances (Soomere et al., 2008). However, on entering they keep propagating along the axis of the Gulf of Finland and affect only very limited sections of the coast of Tallinn Bay, the northern part of which is additionally sheltered by the islands of Aegna and Naissaar (Fig. 1). The same is also true for waves excited in the Gulf of Finland by easterly winds. The roughest seas in Tallinn Bay occur during NNW storms that have fetch length in the order of $100 \mathrm{~km}$ and, thus, only produce waves with relatively short periods. These features severely limit the periods of the wave components. The peak periods of wind waves are usually well below $3 \mathrm{~s}$, reaching $4-6 \mathrm{~s}$ in strong storms and only in exceptional cases do they exceed 7-8 s.

As a result of these factors, the local wave climate is relatively mild in Tallinn Bay compared with the adjacent sea areas. The significant wave height exceeds $0.5-0.75 \mathrm{~m}$ in the bay with a probability of $10 \%$ and $1.0-1.5 \mathrm{~m}$ with a probability of $1 \%$ (Soomere, 2005). On the other hand, very high (albeit relatively short) waves occasionally occur during strong NW-NNW winds, to which Tallinn Bay is fully open. The significant wave height typically exceeds $2 \mathrm{~m}$ at a certain time each year and may reach $4 \mathrm{~m}$ in extreme NNW storms in the central part of the bay. As a consequence, most of the coast of Tallinn Bay has preserved features, indicative of periods of intense erosion (Lutt and Tammik, 1992; Kask et al., 2003) and, as such, it can be considered to be a medium- or high-energy coastal environment.

The wind-wave measurements were performed at the SW coast of Aegna in the Tallinn Bay (Fig. 1). The island, about $1.5 \times 2 \mathrm{~km}$ in size, is located at the northern entrance of Tallinn Bay. It is separated from the Viimsi Peninsula by a shallow-water (typical depth 1-1.5 m) channel with two small islands. Effectively, no wave energy enters Tallinn Bay from the east.

The experimental site is fully open to the south. The maximum fetch length in this direction, however, is only some $10 \mathrm{~km}$. Although the majority of storms blow from the SW, they produce no large waves. Moreover, these waves approach the shore perpendicularly. Significant wave energy enters Tallinn Bay from the north but the study site is sheltered from these waves by the island and shallow water about $300 \mathrm{~m}$ to the west. The most significant waves at the study site and along the adjacent shore to the west, come from the west, entering Tallinn Bay between the mainland and the island of Naissaar. Waves from the NW are effectively blocked by Talneem Point (the W-SW end of Aegna, Fig. 1) and even if they reach the SW coast owing to refraction, they impact the coast in a similar way to waves approaching from the west. 
Towards Talneem, from the study site, a very shallow area extends seaward, some $300 \mathrm{~m}$ from the coast, where water depths increase over a short distance. In the vicinity of the study site, water depths increase over a short distance to approximately $2 \mathrm{~m}$, beyond which there is a more or less linear slope from the position of the tripod on which the measuring equipment was mounted down to depths of 6-8 $\mathrm{m}$ and a gently sloping terrace, $0.5-1 \mathrm{~km}$ wide to about $15 \mathrm{~m}$ water depth.

High resolution time series of water surface elevations were collected using an ultrasonic echosounder LOG_aLevel ${ }^{\circledR}$ from General Acoustics. The measurement range of the sensor was $0.5-10 \mathrm{~m}$ to the water surface with an accuracy of $\pm 1 \mathrm{~mm}$. The surface water elevation data were collected almost continuously over 30 days ( 21 June-20 July 2008) at a recording frequency of $5 \mathrm{~Hz}$. The device was mounted at a distance of about $100 \mathrm{~m}$ offshore from an effectively non-reflecting shore of the island of Aegna at a depth of $\sim 2.7 \mathrm{~m}$. A part of the experiment was performed in almost calm conditions (significant wave height below $10 \mathrm{~cm}$ ). The typical significant wave height was $30 \mathrm{~cm}$ and the height reached $60 \mathrm{~cm}$ during short time intervals.

Although the overall wave conditions in the study region are relatively low, freak wave events do occur there. Freak waves were taken to be those whose wave height was more than twice as large as significant wave height $H_{\mathrm{f}}>2 H_{\mathrm{s}}$ (Kharif et al., 2009). Of course, the height of these waves varies with the height of the background from calm to stormy days. Nevertheless, we analyse all measured waves which satisfy the defining condition for freak waves to get as complete a picture as possible of processes occurring in the coastal zone of the Baltic Sea. The analysis of the record revealed several unexpectedly high and steep waves with periods close to the typical periods of the wind waves. The most prominent freak wave event was recorded on 9 July 2008 at $22 \mathrm{~h} 59$ (Fig. 2). Its height and period were $1.2 \mathrm{~m}$ and $5 \mathrm{~s}$, respectively, when significant wave height was about $40 \mathrm{~cm}$ and the peak period about $4 \mathrm{~s}$. The height of this freak wave, therefore, exceeded the significant wave height by a factor of about 3. The wave arrived without any warning or "hole" ahead of it; instead, it was followed by a deep trough (about $40 \mathrm{~cm}$ ). The wave was highly asymmetric: its crest reached over $80 \mathrm{~cm}$ whereas the typical crest elevation was below $20 \mathrm{~cm}$.

\section{Recorded freak waves: their typical properties}

Here, we present an overall description of the freak wave data. Since Tallinn Bay has very intense ship traffic during the day time, we consider only pure wind-wave data recorded at night time (from 0 to $07 \mathrm{~h} 00$ ). Additionally, signals, resembling ship wakes that are characterised by different periods, have been excluded from the analysis. The heights of all waves which occurred between $00 \mathrm{~h} 00$ and $07 \mathrm{~h} 00$ each day

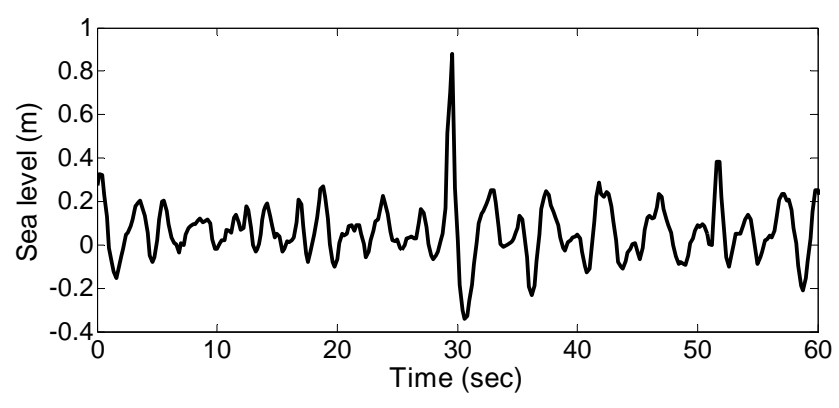

Fig. 2. The freak wave record on 9 July 2008.

were calculated using the down-crossing method. The significant wave height, which is an average of $1 / 3$ of the highest waves, was assumed to be constant in 20-min intervals and was calculated within every 20 -min interval. The use of a 20-min interval is usual for deep-water waves (for example, Stansell, 2004) and the same interval has been used for analysis of freak waves in the coastal zone of the Black Sea (Cherneva et al., 2005). In the present data, there are 609 such 20-min intervals during 29 days of measurements, containing $\sim 400000$ wind waves of which 97 are identified as freak waves. A Rayleigh distribution of crest height, appropriate under a narrow-band Gaussian model for the sea surface elevation in deep water, would suggest that a freak wave $\left(H_{\mathrm{f}}>2 H_{\mathrm{s}}\right)$ would occur about once in every 3000 wave events (Kharif et al., 2009); that is, about 130 times for our number of waves, which is close to the recorded number. It is known, however, that the Rayleigh distribution does not, in general, give a good description of wave heights in shallow water (Glukovskij, 1966; Bitner, 1980), a fact borne out of the present experiment by there being 3 freak waves with $H_{\mathrm{f}}>3 H_{\mathrm{s}}$, although the Rayleigh distribution gives a very small probability $\left(<10^{-10}\right)$ for waves of this height.

It should be mentioned here that we do not apply any height limitations to our freak waves and consider as freak waves less than $1 \mathrm{~m}$ height if the condition $H_{\mathrm{f}}>2 H_{\mathrm{s}}$ is satisfied. Of course, not all of these freak waves are dangerous. At the same time, the criterion of danger is different when you consider the breakage of a structure or the death of a person. The situation for the coastal zone, where many people are swimming and walking around, should be different from the open ocean where the wave needs to be really great to destroy something. As is known, even a $0.5-\mathrm{m}$ water flow on the coast can be hazardous. The typical velocity of such a flow is about $2 \mathrm{~m} / \mathrm{s}$ and is strong enough to knock a person off his feet and to kill him. Such events were mentioned in our paper (Didenkulova et al., 2006). During our experiment in Tallinn Bay, we measured 44 waves with the wave height exceeding $0.5 \mathrm{~m}$ and 3 waves with the height more than $1 \mathrm{~m}$.

Typical shapes of recorded freak waves are presented in Fig. 3. All 97 of the freak waves were solitary waves of a positive, negative or sign-variable shape. The positive shape was defined as the shape of the wave, whose crest is more than 

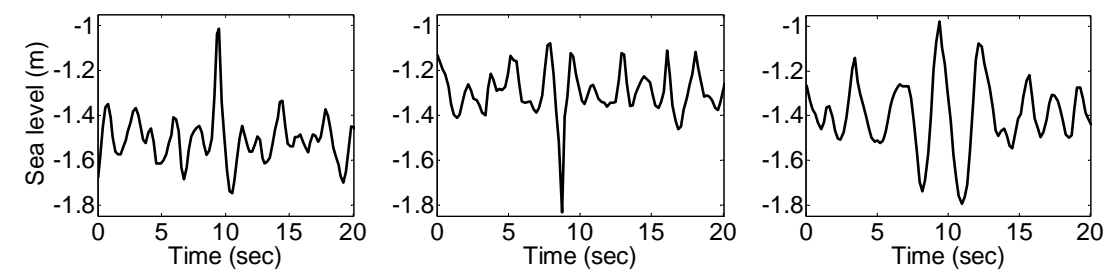

Fig. 3. Typical positive (left), negative (middle) and sign-variable (right) shape of freak waves in Tallinn Bay occurred at $04 \mathrm{~h} 06$ on $22 \mathrm{June}$, at $04 \mathrm{~h} 27$ on 24 June and at $03 \mathrm{~h} 55$ on 26 June 2008, respectively; the sea level is measured relative to the location of the echosounder.

$50 \%$ higher than its trough with respect to the mean sea level. Analogously, waves with negative shapes were those, whose troughs are more than $50 \%$ greater than their crests. Other waves were considered as a sign-variable shape. Waves of positive and a mixed type are quite typical for deep water as well, while waves of negative shape are quite specific and can be a speciality for coastal waters. No group of freak waves made up of two or three (the famous shape of freak waves known as "three sisters") consecutive freak waves (see, for example, Kharif et al., 2009) were recorded. A majority of the waves (61 events or $63 \%$ of waves) had a positive shape. The number of sign-variable or negative wave shapes was three times smaller: 19 events or $19.5 \%$ of waves had signvariable and 17 or $17.5 \%$ of waves had negative shape.

The asymmetry of freak waves occurring in deep waters has been discussed in (Guedes Soares et al., 2004). The present freak waves from shallow waters in Tallinn Bay were also asymmetric. At the same time, waves of negative shape in the dataset were more asymmetric in terms of face-back asymmetry than positive and sign-variable waves, confirming the conclusion of the nonlinear shallow water wave theory that wave asymmetry and wave breaking affect the wave trough more than the wave crest (Didenkulova et al., 2007; Zahibo et al., 2008). The back front of the observed negative waves was steeper than the face front; while in the case of positive or sign-variable waves the face front was steeper, as predicted by the theory (Didenkulova et al., 2007; Zahibo et al., 2008). The fact that waves of sign-variable shape have less asymmetry than freak waves of positive or negative shape can be explained by wave nonlinearity. Such waves have smaller deviation from the mean water level and they are less nonlinear than corresponding positive or negative waves of the same height. This also explains the fact that even within one wave category freak waves of a smaller height are less asymmetric.

The scatter diagram of freak wave height $H_{\mathrm{f}}$ and significant wave height $H_{\mathrm{s}}$ for different wave shapes is presented in Fig. 4. Observations are mostly close to the $H_{\mathrm{f}}=2 H_{\mathrm{s}}$ line with a few weak deviations mainly for waves of negative shape. These deviations are even more evident in Fig. 5, where the amplification factor (the ratio of the freak wave height $H_{\mathrm{f}}$ to significant wave height $H_{\mathrm{s}}$ ) for different wave shapes is shown.

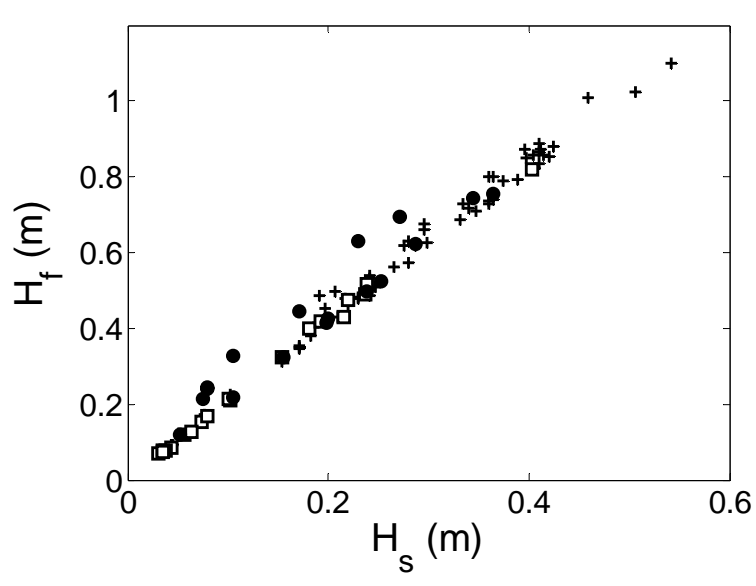

Fig. 4. Scatter diagram of freak wave height $H_{\mathrm{f}}$ and significant wave height for positive (crosses), negative (circles) and sign-variable (squares) freak waves.

In Fig. 5, the amplification factors in most of the freak waves are seen to vary from 2 to 2.4 and do not appear to depend on significant wave height. This first group of freak waves, Group I, is outlined with a dashed rectangle in Fig. 5. All symmetrical and almost all positive freak waves belong to this group. The remaining few waves have larger amplification, which appears to decrease on average with increasing $H_{\mathrm{s}}$. These waves represent the Group II, which is well separated from the first. It is outlined by the ellipse in Fig. 5. The majority of waves in this group have a negative shape. The decrease of the amplification factor with significant wave height can be explained by the process of wave breaking, which more strongly affects nonlinear waves of a larger amplitude. At the same time, negative waves are more subject to the breaking phenomenon and, even in the case of sine wave propagation in a basin of constant slope, breaking usually occurs at the trough of the wave (Zahibo et al., 2008). This can be seen in Fig. 6, where enlargements of the positive and negative freak wave records from Fig. 3 are presented. In contrast to the positive freak wave in Fig. 6, the negative wave has a very sharp ending that can reflect the process of wave breaking. 


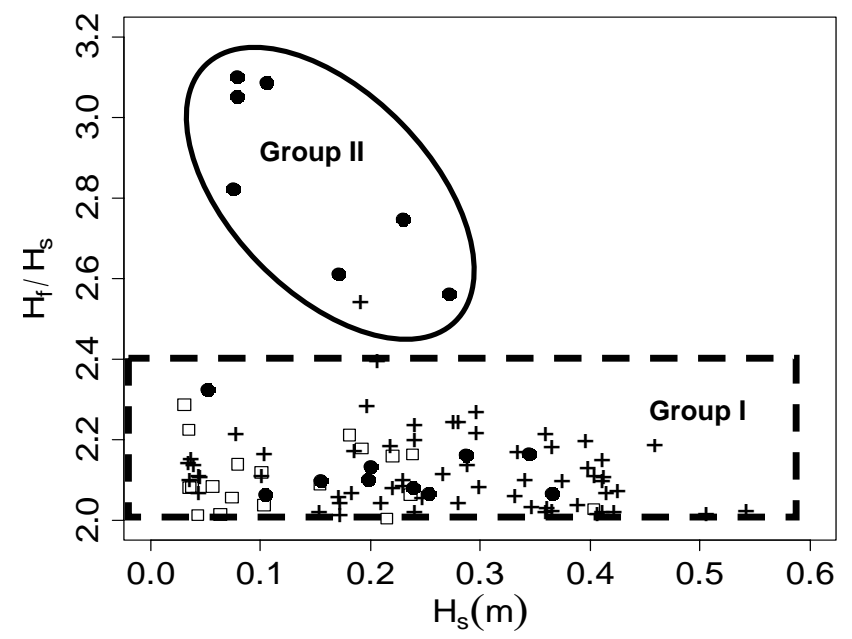

Fig. 5. Amplification factor plotted against significant wave height for positive (crosses), negative (circles) and sign-variable (squares) freak waves.

\section{Evidence for two groups}

Though the visual impression created by Fig. 5 suggests the presence of two groups of observations, it might be argued that the pattern of plotted points could be a result of a random selection from a single population and that apparent dependence of the amplification factor $A=H_{\mathrm{f}} / H_{\mathrm{S}}$ on $H_{\mathrm{S}}$ for some waves is nothing more than a coincidence. However, a simulation (permutation) test of the hypothesis of no correlation between $A$ and $H_{\mathrm{s}}$ (based on the comparison of the observed correlation with the correlation values calculated by randomly permuting the $H_{\mathrm{s}}$ observations) shows strong evidence against the possibility that the dependence of $A$ on $H_{\mathrm{S}}$ is illusory; there is strong evidence of a relationship ( $p$ value $=0.013$ ). The possibility that Fig. 5 could have been generated from a homogeneous population of freak waves with a dependence on $H_{\mathrm{s}}$ nevertheless remains. This question may be discussed in terms of Generalised Pareto distributions, the family of distributions appropriate for data observed over a high threshold (Coles, 2001). The relevance of these distributions to high values rests on limiting arguments (De Haan, 1971; Pickands, 1975) which show that under mild conditions the conditional distribution of the excess of an observation over a high threshold, given that the observation exceeds the threshold, approximates to a Generalised Pareto distribution as the threshold increases. Almost all standard continuous distributions satisfy the conditions, so that the Generalised Pareto family permits the statistical modelling of high observations without the assumption of a specific analytic form for the distribution of the variable of interest at high levels (something for which there is usually little empirical evidence), and with the knowledge that conclusions will be consistent with a very wide range of distributional tail behaviour. The Generalised Pareto distribution
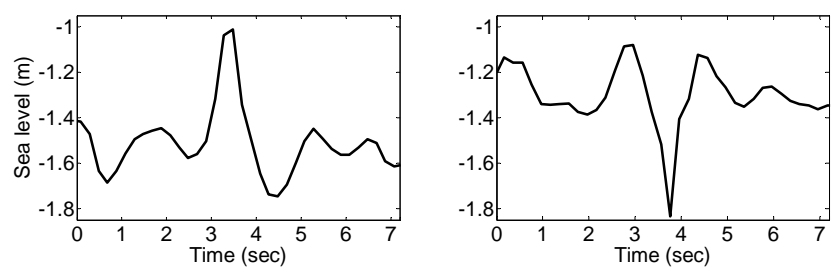

Fig. 6. Enlargement of positive (left) and negative (right) freak wave traces presented in Fig. 3.

has been used to describe short-term characteristics of freak waves, wave crests and troughs by Stansell (2005). Its application demands care, particularly in the choice of threshold, which needs to be high enough for the limiting result to give a reasonable approximation but not so high that there are too few exceedances to permit reliable estimation; Naess and Clausen (2000) discuss this issue for the case of Gaussian observations and moment-based estimators. Simple general diagnostics for threshold adequacy are provided by mean excess plots and QQ plots (Davison and Smith 1990; Coles, 2001) and are used in the discussion below.

The distribution function of a Generalised Pareto distribution for values of $A=H_{\mathrm{f}} / H_{\mathrm{s}}$ exceeding a threshold $u$ is

$\operatorname{Pr}(A \leq a)=G(a)=1-\left(1+\frac{\xi}{\sigma}(a-u)\right)^{-1 / \xi},(a>u)$,

where $\xi$ and $\sigma>0$ are shape and scale parameters, respectively. We investigate whether the observed values of $A$ above the threshold $u=2$ are consistent with a Generalised Pareto distribution in which the scale parameter varies with $H_{\mathrm{S}}$ according to $\ln (\sigma)=\alpha+\beta H_{\mathrm{S}}$ for some constants $\alpha$ and $\beta$, a form conveniently representing increasing or decreasing dependence on $H_{\mathrm{s}}$ whilst continuing to ensure positivity of $\sigma$. The distribution (1) with varying $\sigma$ may be fitted by maximum likelihood estimation using, for example, the R package ismev ( $R$ 2009). The fitting shows that there is strong evidence, under the assumption of a Generalised Pareto distribution, that $\beta$ is non-zero and so that $\sigma$ varies with $H_{\mathrm{S}}$ (GLR test; $p$-value 0.005 ). Adequacy of the fitted distribution may be assessed by the transformed QQ plot shown in Fig. 7 . Figure 7 plots the ordered values of $(1 / \hat{\xi}) \ln (1+\hat{\xi}(a-2) / \hat{\sigma})$, where $\hat{\sigma}=\exp \left(\hat{\alpha}+\hat{\beta} H_{\mathrm{s}}\right)$ and $\hat{\xi}$ are maximum likelihood estimates and $a$ denotes the observed augmentation factors, against quantiles of the unit exponential distribution. If observations follow the Generalised Pareto distribution (1) with $\sigma$ varying in this way, then the transformed values follow the unit exponential distribution. Thus, a quantile-quantile plot in which all points lie close to the $45^{\circ}$ line would support the model (1) with varying $\sigma$.

From Fig. 7 it is clear, however, that there is substantial deviation from the line at high values and, therefore, that a common Generalised Pareto distribution with smoothly varying $\sigma$ does not adequately describe the observations. It is the 
QQ plot on Exponential scale: all data

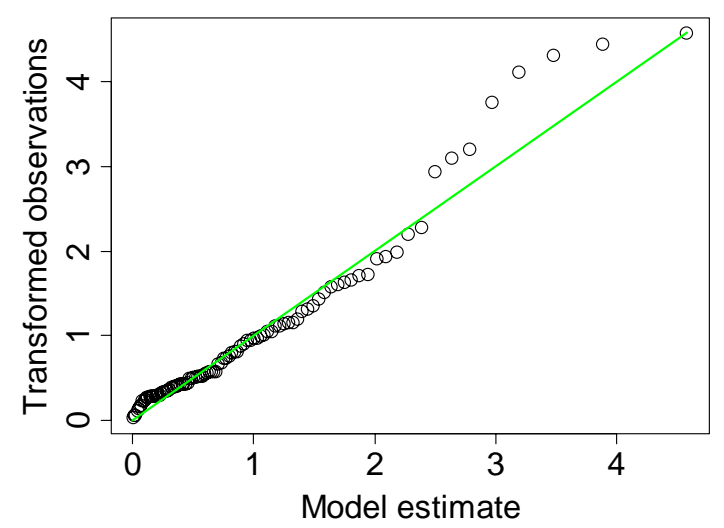

Fig. 7. Transformed exponential scale QQ plot of amplification factors based on Generalised Pareto distribution with $\ln (\sigma)=\alpha+\beta H_{\mathrm{S}}$; all data.

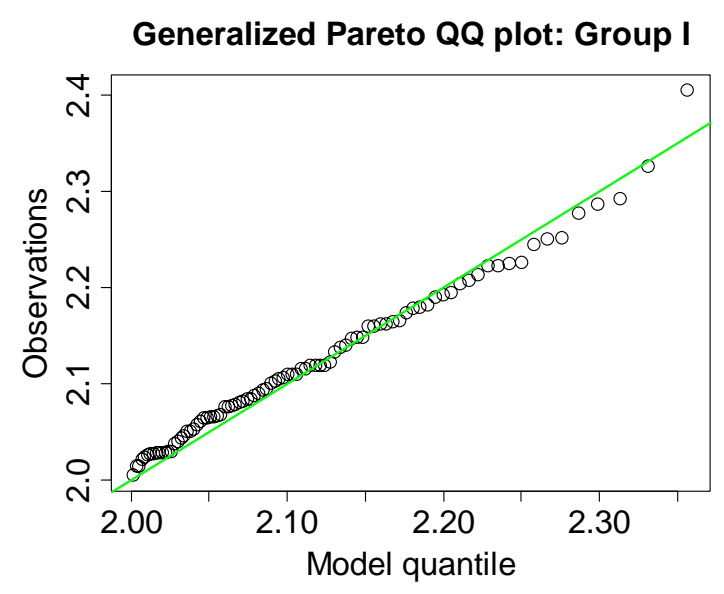

Fig. 8. QQ plot of amplification factors based on a Generalised Pareto distribution with constant parameters; Group I data.

largest 8 observations that are aberrant and a tentative suggestion is that they come from a different population. Thus, arises the tentative separation of observed freak waves into the two groups shown in Fig. 5.

\section{Freak waves of Group I}

The first group of freak waves contains 89 observations with amplification factors ranging from 2.00 to 2.40 . We explore a Generalised Pareto model for these data by first fitting such a distribution with a varying scale factor $\sigma$ as above, and comparing it with a Generalised Pareto distribution in which both $\sigma$ and $\xi$ are constant (a similar analysis, GPD, has also been applied to surface waves in deep waters of the North Sea, Stansell, 2005). A GLR test to compare the two models shows no evidence now of the earlier dependence of $\sigma$ on $H_{\mathrm{S}}$ ( $p$-value 0.16 ) and, thus, supports a simple Generalised

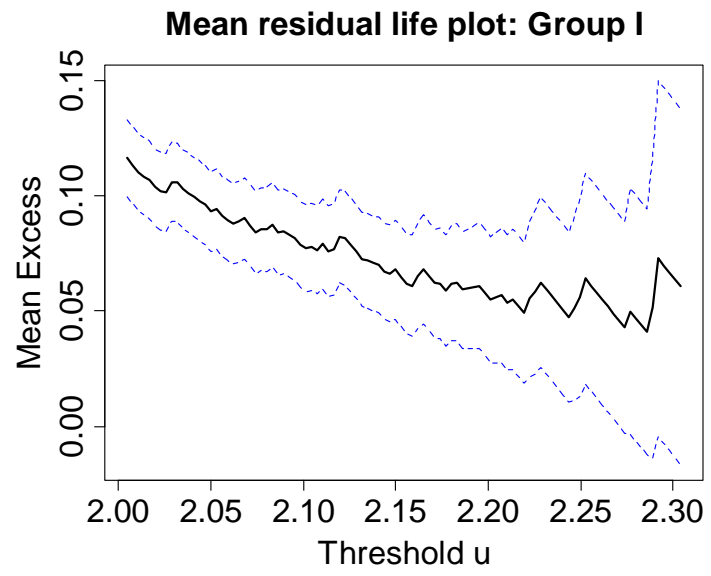

Fig. 9. Mean residual life plot for wind waves in Tallinn Bay, Baltic Sea; Group I observations. The solid curve represents mean residual life and the dotted curves the approximate pointwise $95 \%$ confidence limits.

Pareto distribution with constant parameters as a model for the Group I observations. How good is the model may be examined by the QQ plot in Fig. 8, the plot of the ordered observations $a_{(i)}, i=1, \ldots, 89$ against $G^{-1}(i /(n+1))$. Points close to an increasing straight line in such plots indicate adequacy of the model.

Figure 8 shows reasonable consistency in the constant model with the data. The estimated parameter values and their standard errors for this model are: $\hat{\sigma}=0.159(0.019)$ and $\hat{\xi}=-0.357(0.066)$.

A further check on adequacy of the constant-parameter Generalised Pareto distribution as a model for the Group I observations is given by the mean residual life (mean excess) plot, which is the locus of points

$\left(u, \frac{1}{n_{u}} \sum_{a_{(i)}>u}\left(a_{\{i\}}-u\right)\right)$,

as the threshold $u$ varies, based on the dataset $a_{(1)} \leq \ldots \leq$ $a_{(89)}$ where $n_{u}$ denotes the number of amplification factors $a$ that exceed threshold $u$. Above a threshold $u_{0}$ at which the Generalised Pareto distribution provides a valid approximation to the excess distribution, the mean residual life plot should be approximately linear in $u$. The mean residual life plot for the Group I observed augmentation factors are shown in Fig. 9.

Again the figure gives no reason to question adequacy of the model for the Group I data. Evidently the choice of a threshold $u=2$ is fully appropriate for a Generalised Pareto description of the Group I observations.

It should be noted that the proposed distribution function for the description of freak waves in the coastal zone is important for many coastal engineering applications. However, it needs to be further verified by other datasets before a firm conclusion about its general applicability can be reached. 


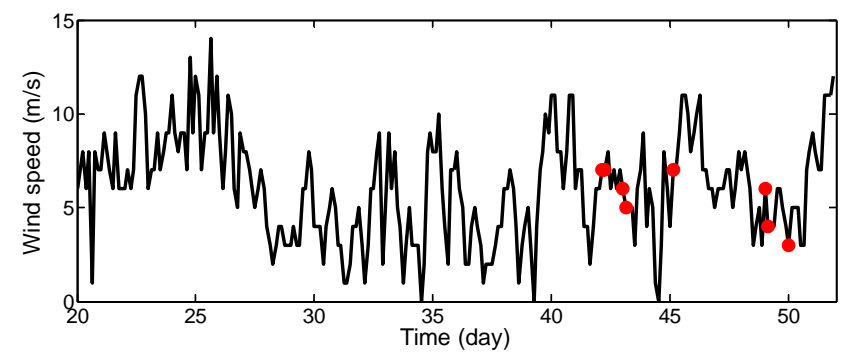

Fig. 10. Wind speed for 20 June-21 July 2008 in Kalbadagrund (Finland); the circles show the times when freak waves of the Group II occurred.

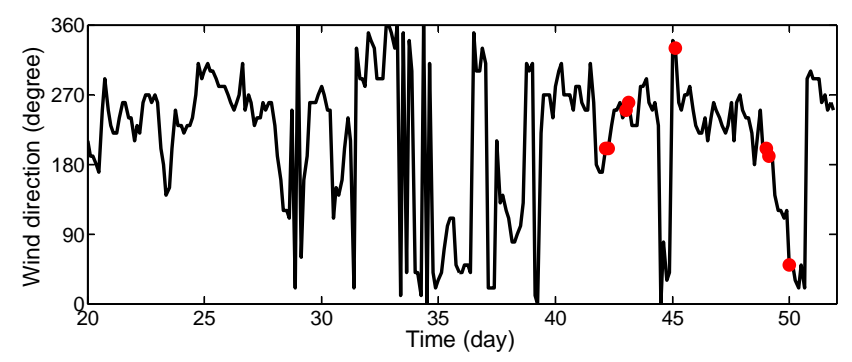

Fig. 11. Wind direction for 20 June-21 July 2008 in Kalbadagrund (Finland); the circles show the times when freak waves of the Group II occurred.

\section{Freak waves of Group II (abnormal freak waves)}

Since the freak waves of the second group differ sharply from others, we should first look at the conditions under which these abnormal waves occurred. It should be mentioned here that all waves of the second group occurred only in the final week of measurements, on 12, 13, 15, 19 and 20 July. The values of the wind speed and wind direction measured in June-July 2008 in Kalbadagrund, Finland (Fig. 1) that are the only reliable wind data for the Gulf of Finland, are presented in Figs. 10 and 11. The circles indicate the freak waves of Group II. Since two freak wave events occurred within the interval of $4 \mathrm{~min}$, they are indicated in Figs. 1012 as a single circle. As can be seen from Figs. 10 and 11, the waves occurred in conjunction with wind speeds from 3 to $7 \mathrm{~m} / \mathrm{s}$ and a rather wide range of wind directions from $50^{\circ}$ to $330^{\circ}$. Thus, we cannot find an explanation of abnormal freak wave occurrence using these wind data only. However, data from Kalbadagrund, which is located in the middle of the Gulf of Finland far from the study site (Fig. 1), may not fully represent conditions in Tallinn Bay where local effects can be significant. From this point of view, the most reliable weather data should be taken directly from the study area.

Significant wave heights and maximum wave heights calculated for all 20-min interval in the dataset are shown in Fig. 12. The figure shows that the freak waves with the

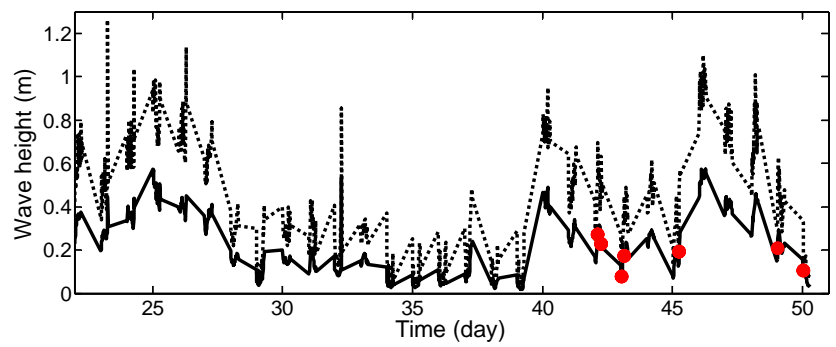

Fig. 12. Significant wave heights (solid line) and maximum wave heights (dotted line) for 20-min intervals of the night data from 22 June-21 July 2008; the circles show the times when freak waves of the Group II occurred.

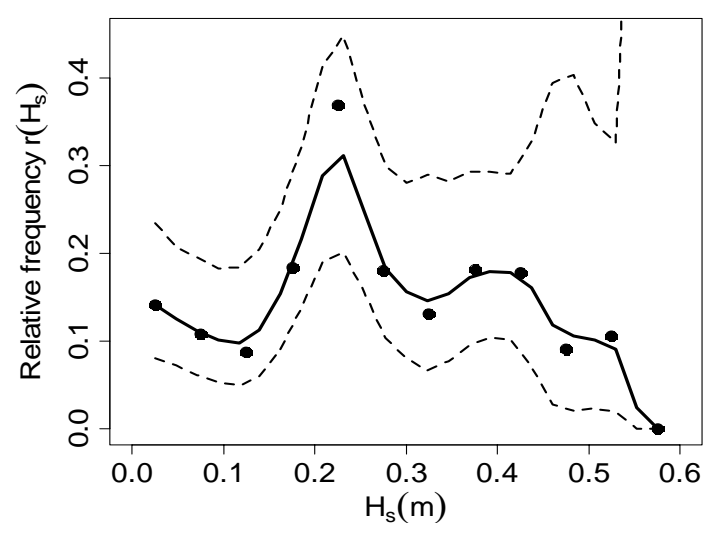

Fig. 13. The relative frequency and estimated probability of freak wave occurrence within a 20-min interval as a function of significant wave height. The dots are observed relative frequencies at $5 \mathrm{~cm}$ intervals of $H_{\mathrm{s}}$. The solid line corresponds to a smoothed logistic regression estimate of the corresponding probabilities and the dotted lines are approximate $95 \%$ confidence intervals.

largest amplification factor occur for values of significant wave height when the sea was in an intermediate state between calm and stormy weather conditions, but at neither extreme.

This fact becomes even more evident from the examination of the relative frequency of freak wave occurrence in relation to significant wave height:

$r\left(H_{\mathrm{s}}\right)=\frac{K\left(H_{\mathrm{s}}\right)}{N\left(H_{\mathrm{s}}\right)}$,

where $K\left(H_{\mathrm{s}}\right)$ is the number of 20-min intervals with significant wave height $H_{\mathrm{S}}$ during which at least one freak wave was observed, and $N\left(H_{\mathrm{s}}\right)$ is the total number of 20-min intervals with significant wave height $H_{\mathrm{s}}$ (with or without freak waves observed). The values of $r\left(H_{\mathrm{s}}\right)$ for $5 \mathrm{~cm}$ intervals of $H_{\mathrm{S}}$ are shown by the dots in Fig. 13. The solid line in the figure is a non-parametric estimate based on smoothed logistic regression of the corresponding probability of freak wave occurrence (Bowman and Azzalini, 1997, R package sm), and 


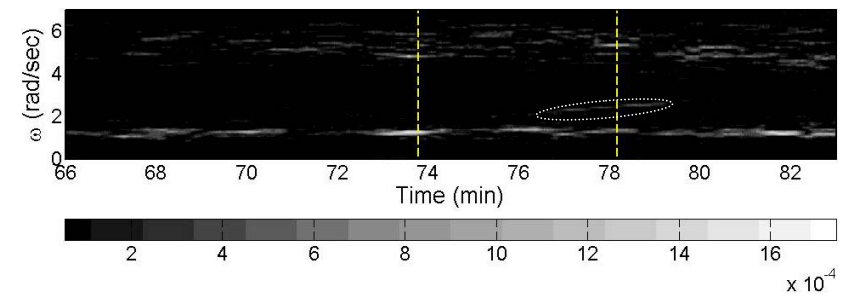

Fig. 14. Time-frequency spectrum (extracts $60 \mathrm{~s}$ ) of the record of 13 July 2008; shades of grey indicate the spectral density; dashed lines correspond to the time of the freak wave occurrence; the ellipse corresponds to the dispersive track.

the two dashed lines show the approximate $95 \%$ confidence intervals for this estimate. The observed relative frequency of freak wave occurrence in Tallinn Bay in the analysed data series (from the period June-July 2008) was at its highest (about 37\%) when significant wave height was in the range of 20-25 cm, whereas for all other values of $H_{\mathrm{S}}$ relative frequency was observed to be less than half as large. Even after the allowance for estimation uncertainty, there is a suggestion that corresponding probabilities of occurrence are highest for $H_{\mathrm{s}}$ close to $20-25 \mathrm{~cm}$.

Over the period of data collection during night-time hours in June-July, there were relatively few (ca. 8\%) 20-min intervals with significant wave height in the $20-25 \mathrm{~cm}$ range, and most of those occurred in the final week of measurements. Furthermore, it is important to mention that the freak waves of Group II occurred at times when significant wave height was in or near the range from 20 to $25 \mathrm{~cm}$ or a short time later as significant wave height was decreasing (Fig. 12). It is known from earlier studies and experimental experience that the range of significant wave heights from 20 to $25 \mathrm{~cm}$ in Tallinn Bay corresponds to intermediate conditions when a storm is approaching or has just come to an end, or when the storm is just passing by. In the case of non-stationary winds (when the storm is approaching or passing by) the Fourier frequency spectrum varies with time. For a particular combination of frequency components in time, when short waves propagate first and long waves afterwards, at a certain moment long waves overtake the short ones and their combination gives rise to a freak wave. This mechanism of freak wave generation is called dispersive focussing and it is known to exist for waves in both deep and shallow waters (Magnusson et al., 1999; Arena et al., 2008; Kharif and Pelinovsky, 2003; Kharif et al., 2009).

The time-frequency spectrum of the record of 13 July 2008, when the largest freak waves of Group II occurred, represents the situation described above. The spectrum is shown in Fig. 14. The dashed lines in Fig. 14 correspond to the time of the freak wave occurrence. It can be seen, that both freak waves occur in the situation of bimodal spectra. There are two major energy concentrations in the Fourier spectrum: one wind-wave system at $1 \mathrm{~s}$ and the other a swell system of peak period $5 \mathrm{~s}$. Moreover, the spectrum for the second (the largest) freak wave (to the right in Fig. 14) has an additional dispersive track (marked by the dotted line in Fig. 14), which can be interpreted as a dispersive focussing. Similar analysis of freak waves in the North Sea is reported in (Slunyaev et al., 2005).

\section{Conclusions}

In this paper, a statistical analysis of freak waves measured during $203 \mathrm{~h}$ in the coastal zone of the Baltic Sea $(2.7 \mathrm{~m}$ depth) in June-July 2008 is presented. This data contains, in total, 97 freak waves which occurred in both calm and stormy weather conditions.

All 97 of these freak waves were solitary waves of positive, negative or sign-variable shape. During the time of measurements no group of freak waves consisting of two or three consecutive freak waves were observed. Most of the waves (63\%) had a positive shape, $19.5 \%$ sign-variable and $17.5 \%$ had negative shape. All waves were asymmetric in terms of face slope-back slope asymmetry. Waves of negative shape were the most asymmetric.

It is suggested that the dataset contains two groups of freak waves distinguished by the value of the ratio of freak wave height to significant wave height, the amplification factor. Amplification factors for Group I, the larger group of the two, vary in range from 2.0 to 2.4 and do not depend on significant wave height $H_{\mathrm{s}}$, while amplification factors of waves in Group II can reach 3.1, and depend strongly on $H_{\mathrm{s}}$. The amplification factors of freak waves from Group I may be regarded as a random sample from a Generalised Pareto distribution with constant parameters.

Freak waves are found to have occurred most often when $H_{\mathrm{S}}$ was in the range from 20 to $25 \mathrm{~cm}$. Significant wave heights in this range, which corresponds to an intermediate case when the sea is neither calm nor stormy, were rarely observed during the month of measurement, and abnormal freak waves from Group II occurred when the significant height of sea waves was near this range, or a short time later when significant wave height had decreased. It is suggested that the probable mechanism of generation of these freak waves is dispersive focussing, though to make a final conclusion on the origin of the mechanism, numerical model simulations under the same sea state conditions should be carried out. Time-frequency spectra of the freak waves are also studied and dispersive tracks, which can be interpreted as evidence of dispersive focussing, are shown.

Acknowledgements. This research is supported partially by Marie Curie network SEAMOCS (MRTN-CT-2005-019374), EEA grant (EMP41), State Contract (02.740.11.0732) and Russian President Program (6734.2010.5).

Edited by: E. Pelinovsky

Reviewed by: two anonymous referees 


\section{References}

Al-Humoud, J., Tayfun, M. A., and Askar, H.: Distribution of nonlinear wave crests, Ocean Eng., 29, 1929-1943, 2002.

Arena, F., Ascanelli, A., Nava, V., Pavone, D., and Romolo, A.: Three-dimensional nonlinear random wave groups in intermediate water depth, Coastal Eng., 55, 1052-1061, 2008.

Bitner, E. M.: Nonlinear effects of the statistical model of shallowwater wind-waves, Appl. Ocean Res., 2, 63-73, 1980.

Bitner-Gregersen, E. M. and Magnusson, A. K.: Extreme events in field data and in a second order wave model, Proc. Rogue Waves 2004, Brest, France, 2004.

Bowman, A. W. and Azzalini, A.: Applied Smoothing Techniques for Data Analysis: the Kernel Approach with S-Plus Illustrations, Oxford University Press, Oxford, 1997.

Caliskan, H. and Valle-Levinson, A.: Wind-wave transformations in an elongated bay, Cont. Shelf Res., 28, 1702-1710, 2008.

Cherneva, Z., Petrova, P., Andreeva, N., and Guedes Soares, C.: Probability distributions of peaks, troughs and heights of windwaves measured in the black sea coastal zone, Coastal Eng., 52, 599-615, 2005.

Chien, H., Kao, C.-C., and Chuang, L. Z. H.: On the characteristics of observed coastal freak waves, Coastal Eng. J., 44(4), 301-319, 2002.

Coles, S.: An introduction to statistical modelling of extreme values, Springer, Berlin, 2001.

Davison, A. C.and Smith, R. L.: Models for exceedances over high thresholds (with discussion), J. Roy. Stat. Soc. B, 52, 393-442, 1990.

Dean, R. G. and Dalrymple, R. A.: Coastal processes with engineering applications, Cambridge University Press, Cambridge, 2002.

De Haan, L.: On regular variation and its application to the weak convergence of sample extremes, Mathematical Center Tracts, Amsterdam, 1971.

Didenkulova, I., Pelinovsky, E., Soomere, T., and Zahibo, N.: Runup of nonlinear asymmetric waves on a plane beach, in: Tsunami and Nonlinear Waves, edited by: Kundu, A., Springer, 173-188, 2007.

Didenkulova, I. I., Slunyaev, A. V., Pelinovsky, E. N., and Kharif, C.: Freak waves in 2005, Nat. Hazards Earth Syst. Sci., 6, 10071015, doi:10.5194/nhess-6-1007-2006, 2006.

Glukovskij, B. Ch.: Research of Wind Waves, Hydrometeor. Publ., Leningrad, 1966.

Guedes Soares, C., Cherneva, Z., and Antao, E. M.: Steepness and asymmetry of the largest waves in storm sea states, Ocean Eng., 31, 1147-1167, 2003.

Kask, J., Talpas, A., Kask, A., and Schwarzer, K.: Geological setting of areas endangered by waves generated by fast ferries in Tallinn Bay, Estonian Journal of Engineering, 9, 185-208, 2003.

Kharif, Ch. and Pelinovsky, E.: Physical mechanisms of the rogue wave phenomenon, Eur. J. Mech. B-Fluid., 22, 603-634, 2003.

Kharif, Ch., Pelinovsky, E., and Slunyaev, A.: Rogue waves in the ocean, Springer, 2009.
Krogstad, K. E., Barstow, S. F., Mathisen, J. P., Lønseth, L., Magnusson, A. K., and Donelan, M. A.: Extreme Waves in the LongTerm Wave Measurements at Ekofisk, Proc. Rogue Waves 2008 Workshop, Brest, France, 13-15 October 2008.

Lutt, J. and Tammik, P.: Bottom sediments of Tallinn Bay, Estonian Journal of Earth Sciences, 41, 81-87, 1992.

Magnusson, A. K., Donelan, M. A., and Drennan, W. M.: On estimating extremes in an evolving wave field, Coastal Eng., 36, 147-163, 1999.

Massel, S. R.: Hydrodynamics of coastal zones, Elsevier, Amsterdam, 1989.

Massel, S. R.: Ocean surface waves: their physics and prediction, World Scientific Publ., Singapore, 1996.

Mori, N. and Yasuda, T.: A weakly non-gaussian model of wave height distribution for random wave train, Ocean Eng., 29, 12191231, 2002.

Neelamani, S., Al-Salem, K., and Rakha, K.: Extreme waves for Kuwaiti territorial waters, Ocean Eng., 34, 1496-1504, 2007.

Olagnon, M.: About the frequency of occurrence of rogue waves, Proceedings of the Rogue Waves 2008 Workshop, Brest, France, 13-15 October 2008.

Petrova, P., Cherneva, Z., and Guedes Soares, C.: Distribution of crest heights in sea states with abnormal waves, Appl. Ocean Res., 28, 235-245, 2006.

Pickands, J.: Statistical inference using extreme order statistics, Ann. Stat., 3, 119-131, 1971.

Prevosto, M., Krogstad, H. E., and Robin, A.: Probability distributions for maximum wave and crest heights, Coastal Eng., 40, 329-360, 2000.

R Development Core Team: R: A language and environment for statistical computing, reference index version 2.10.0, R Foundation for Statistical Computing, Vienna, Austria, 2009.

Slunyaev, A., Pelinovsky, E., and Guedes Soares, C: Modeling freak waves from the North Sea, Appl. Ocean Res., 27, 12-22, 2005.

Soomere, T., Behrens, A., Tuomi, L., and Nielsen, J. W.: Wave conditions in the Baltic Proper and in the Gulf of Finland during windstorm Gudrun, Nat. Hazards Earth Syst. Sci., 8, 37-46, doi:10.5194/nhess-8-37-2008, 2008.

Soomere, T.: Wind wave statistics in Tallinn Bay, Boreal Environ. Res., 10, 103-118, 2005.

Stansell, P.: Distributions of extreme wave, crest and trough heights measured in the North Sea, Ocean Eng., 32, 1015-1036, 2005.

Toffoli, A., Lefevre, J. M., Bitner-Gregersen, E., and Monbaliu, J.: Towards the identification of warning criteria: analysis of a ship accident database, Appl. Ocean Res., 27, 281-291, 2005.

Walker, D. A. G., Taylor, P. H., and Eatock Taylor, R.: The shape of large surface waves on the open sea and the Draupner New Year wave, Appl. Ocean Res., 26, 73-83, 2004.

Young, I. R. and Babanin, A. V.: The form of the asymptotic depthlimited wind-wave spectrum. Part II - The wavenumber spectrum, Coastal Eng., 56, 534-542, 209.

Zahibo, N., Didenkulova, I., Kurkin, A., and Pelinovsky, E.: Steepness and spectrum of nonlinear deformed shallow water wave, Ocean Eng., 35, 47-52, 2008. 